\title{
Correction to: An Improved Isothermal Absorption Equation of Gaseous Molecules under Low Pressure in Gas-Solid System
}

\author{
Liujiao Bian ${ }^{1}$ Yan Zhang ${ }^{1}$
}

Published online: 31 January 2018

(C) ASM International 2018

\section{Correction to:}

J. Phase Equilib. Diffus. https://doi.org/10.1007/s11669-017-0613-0

Yan Zhang's affiliation: College of Life Science, Northwest University, Xi'an, People's Republic of China.

We regret that the original article contained an incorrect author name. It was listed as Penghui Shi and should have been Yan Zhang.

The original article can be found online at https:// doi.org/10.1007/s11669-017-0613-0.

Liujiao Bian

bianliujiao@sohu.com

1 College of Life Science, Northwest University,

Xi'an 710069, Shaan'xi, People's Republic of China 